\title{
Correction to: Towards a consensus definition of maternal sepsis: results of a systematic review and expert consultation
}

\author{
Mercedes Bonet ${ }^{1 *}$, Vicky Nogueira Pileggi ${ }^{2}$, Marcus J. Rijken ${ }^{3}$, Arri Coomarasamy ${ }^{4,5}$, David Lissauer ${ }^{6}$, \\ João Paulo Souza ${ }^{1}$ and Ahmet Metin Gülmezoglu'
}

\section{Correction}

After publication of the original article [1], it came to the authors' attention that the Acknowledgements section was not completed correctly. The Acknowledgements of the article should have been as follows.

\begin{abstract}
Acknowledgements
We gratefully acknowledge contributions of participants to the in-person technical consultation (in alphabetical order): Edgardo Abalos (Rosarinian Center for Perinatal Studies, Argentina), Aniekan Abasiattai (University of Uyo Teaching Hospital, Nigeria), Linda Bartlett (John Hopkins University, USA), Fernando Bellissimo Rodrigues (University of São Paulo, Brazil), Maria Fernanda Escobar Vidarte (Fundación Valle del Lili, Colombia), Carlos Füchtner (FIGO, President Elect), Asmae Khattabi (National School of Public Health, Morocco), Elizabeth Kizzier (Jhpiego, USA), Zahida Qureshi (Kenyatta University, Kenya), Sadia Shakoor (The Aga Khan University, Pakistan), Jeffrey Smith (Jhpiego, USA), Claudio G. Sosa (Latin American Center for Perinatology, Women and Reproductive Health (CLAP), Uruguay), Jos van Roosmalen (VU University Amsterdam, The Netherlands). Special thanks are also due to all of the respondents who anonymously participated in our online survey.
\end{abstract}

\section{Author details}

${ }^{1}$ UNDP/UNFPA/UNICEF/WHO/World Bank Special Programme of Research, Development and Research Training in Human Reproduction (HRP), Department of Reproductive Health and Research, World Health Organization, Geneva, Switzerland. 'Department of Social Medicine and Department of Paediatrics, Ribeirão Preto Medical School, University of São Paulo, Ribeirão Preto, SP, Brazil. ${ }^{3}$ Department of Obstetrics and Gynaecology and Julius Global Health, Julius Center for Health Sciences and Primary Care, Utrecht University Medical Centre, Utrecht, The Netherlands. ${ }^{4}$ Institute of Metabolism and Systems Research, University of Birmingham, Birmingham, UK. ${ }^{5}$ Birmingham Women's National Health Service (NHS) Foundation Trust, Birmingham, UK. 'Birmingham Centre for Women's and Children's Health, College of Medical and Dental Sciences, University of Birmingham, Birmingham, UK.
Published online: 08 January 2018

\section{Reference}

1. Bonet, et al. Towards a consensus definition of maternal sepsis: results of a systematic review and expert consultation. Reproductive Health. 2017;14:67. https://doi.org/10.1186/s12978-017-0321-6.

\footnotetext{
* Correspondence: bonetm@who.int

1 UNDP/UNFPA/UNICEF/WHO/World Bank Special Programme of Research,

Development and Research Training in Human Reproduction (HRP),

Department of Reproductive Health and Research, World Health

Organization, Geneva, Switzerland

Full list of author information is available at the end of the article
} 